\title{
Investigation of Electromagnetic Radiation Emission during Sheet Metal Incremental Micro Forming
}

\author{
Manish Oraon ${ }^{a}$, Vinay Sharma ${ }^{b *}$ \\ ${ }^{a}$ Department of Production Engineering, Birla Institute of Technology, Off Campus-Patna, India \\ ${ }^{b}$ Department of Production Engineering, Birla Institute of Technology, Mesra, India
}

Received: July 5, 2016; Revised: October 28, 2017; Accepted: November 10, 2017

Edge dislocations within the plastic zone ahead of a crack tip form accelerated electric line dipoles which give rise to the electromagnetic radiation (EMR) emissions in metal and alloys. This paper reports an experimental investigation to determine EMR radiation during incremental microforming of a thin aluminum sheet. The EMR signals emit from aluminum grade Al3003 during deformation under unrestricted quasi-static micro-deformation is reported. The EMR emission characteristics are influenced by the microstructural changes rather than forming parametric conditions. The EMR emissions are followed by micro-deformation locally in predetermined loci in continuous deformation pattern through a rotating tool with two different depths. The nature, amplitude and frequency of the observed EMR emissions are in conformity with the predictions of the theoretical model developed by the Misra and co-authors. ${ }^{24-29}$

Keywords: SMIMF, EMR, Step Depth, Microstructure, Input Variables

\section{Introduction}

Incremental micro-forming (IMF) for sheet metals are suitable for low and medium batch production, customized product and rapid-prototyping. The Production cost of Sheet metal Incremental micro-forming (SMIMF) is less than that of other sheet metal forming (SMF) techniques as it does not require costlier \& specialized tools or dies. Instead, the process uses a single point generic tool to produce the product. The Path of the tool is controlled by a CNC machine. In SMIMF, the sheet is deformed locally according to predefined loci and formed the final geometry at the end of the process. Therefore, the main controlling parameter in this technique is the rate of deformation at any point on the sheet. ${ }^{1-7}$ Other challenges for the accuracy of SMIMF are tool geometry, linear \& rotational movement of the tool, sheet metal characteristic, and lubrication media. A number of research works have been reported and analyzing these parameters. The effects of varying tool rotational speed and feed rate on the formability of sheet metal has been investigated by the author and concluded that the tool rotational speed and the feed rate affect the Single point incremental forming (SPIF) formability of sheet metal. The tool rotational speed has more effect on formability compare to feed rate and it also increases roughness and wears off the specimen whereas the tool feed rate has a minimal effect on formability. ${ }^{8}$ The effect of variation of wall angle $\left(\theta_{\max }\right)$ during incremental forming on the formability of aluminum sheetform either a cone or a pyramid with the constant wall angle of angle without fracturing. ${ }^{9}$ The experimental as well as theoretical investigation with process parameters for the

*e-mail: vinay@bitmesra.ac.in determining the forming limit diagram (FLD) of metal and force components in the incremental sheet metal forming (ISMF) process. Experimental and numerical results have been found to be in a good agreement. ${ }^{10}$ The variation of tool step down and tool end radius on the ductile fracture and forming limit curves at fracture (FLCF) of a magnesium alloy sheet was predicted by using the Finite Element (FE) simulation. ${ }^{11}$ A new theory, named the 'noodle' theory which shows the local nature of deformation in SMIMF. The model combined with finite element analyses to predict the occurrence of fracture in SMIMF of two shapes, a cone, and a funnel. ${ }^{12}$ The impact of tool rotation and the forming limit diagram has been investigated to drive the metal behavior. ${ }^{13-16}$

In the present research work, the authors are reporting first time the emission of EMR during SMIMF. These EM Radiation scan be used to understand deformation behaviour online and predict the fracture behaviour. This will help the researcher to understand the conditions under which a material can be deformed to a maximum.

EMR radiation during metal deformation is not new. Many researchers have used the EMR emitted during metal deformation to understand its fracture mechanism. A physical model proposed for electromagnetic radiation emitted during dislocation of electron interaction in a metal. The model predicts the emission of electromagnetic wave during distinct transition stages of elastic-plastic deformation. ${ }^{17}$ Later on, the model, also known as, "Misra Effect" was confirmed. ${ }^{18}$ The model state that, when an externally applied stress increases, edge dislocations within the plastic zone ahead of a crack tip form accelerated electric line dipoles which give rise to the EMR emissions. The dynamic motion of these dislocations 
becomes overdamped, underdamped or critically damped, depending upon the material/microstructural properties. The EMR has a continuous frequency spectrum with a frequency bandwidth ranging from $10^{8}$ to $10^{12}$ radians $\mathrm{s}-1$, depending upon the properties of the metals. Based on the "Misra effect", several researchers have found the intermolecular arrangement of a metallic structure provides strength, rigidity and resist against the externally applied load. ${ }^{19-21}$ Electrical and electromagnetic effects associated with the deformation and fracture of materials has received continuous attention over the past several decades. The electromagnetic radiation (EMR) reported during crack propagation and fracture and the effect of modes of fracture, physical properties and high temperature on the characteristics of emitted EMR. ${ }^{22}$ The EMR emissions in ASTM B265 grade 2 titanium sheets was experimentally investigated and observed the nature of the EMR emission (damped sinusoidal and exponential decay), amplitude, and its frequency in conformity with the predictions of the theoretical model. ${ }^{23}$ The influences of surface anisotropy and grain structure in the emission of EMR by experimental investigation on titanium specimens under compression testing and proposed the use of EMR to evaluate the degree of damage in metallic components under compression. ${ }^{24}$ Further, the effect of processing parameters such as timing of the EMR emissions, maximum stress during crack instability, stress-intensity factor, the elastic strain energy release rate on the emission of electromagnetic radiation (EMR) during plastic deformation and crack propagation in copper-zinc alloys has been investigated. ${ }^{25-29}$ Using this principle, a new area has been explored to find out the EMR emission in the thin sheet of aluminum of few millimeter thicknesses which is deformed by a small tool with hemispherical end particularly known as sheet metal incremental micro-forming.

The present research work summarizes the experimental investigation of incremental micro- deformation of a thin aluminum sheet using hemispherical end rod (tool) of 3 $\mathrm{mm}$ radius at the end. The EMR radiation emitted during deformation captured by the antenna and filter developed for the purpose. The results are correlated with the deformation characteristics of the metal.

\section{Experimental Investigation}

Experimentations are carried out in the high precision machining center (MIKROTOOLS DT110) having the position accuracy of \pm 1 micron. Incremental micro deformations are being made on the commercial aluminum sheet (A13003-O) of $0.2 \mathrm{~mm}$ thickness. The workpiece is clamped at its edges for respective experimentation on a six-degree freedom table. Micro deformations on the workpiece are obtained by the relative movement of the tool with respect to the blank. The tools are made by inserting high-speed steel (HSS) ball of diameter six mm into the groove made at the head of the rod. Flowchart of the investigation is summarized in Fig. 1.

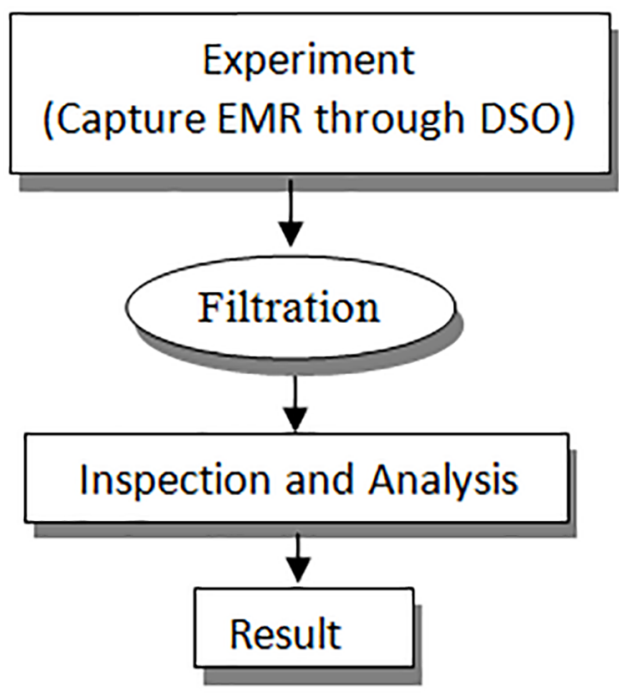

Figure 1. Flowchart of Experimental Design.

\subsection{Sample preparation for experiments}

Work samples of size $50 \mathrm{~mm}$ x $46 \mathrm{~mm}$ are prepared from $0.2 \mathrm{~mm}$ thick Al3003-O sheet. Copper strips of size $15 \mathrm{~mm} \times 2 \mathrm{~mm} \times 0.2 \mathrm{~mm}$ are pasted randomly on the reverse side of the sheets to act as an antenna for pivots run (Fig.2). EMR emitted during deformation is captured by the antenna connected to the digital storage oscilloscope (DSO) by wires. Further, it is noted that a large number of EMR is captured in real time scale when the long side of the antenna positioned along the tool path compared to across it (Fig 3). This is because of the long time the tool remains in contact with the antenna.
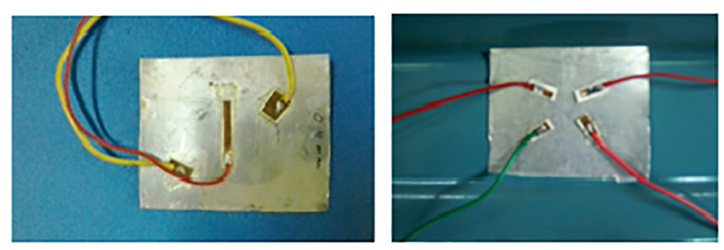

Figure 2. The fixation of antenna randomly for Antenna to capture EMR radiation.

Initially, there are the difficulties in capturing the EMR signals emitted. This has been rectified by placing four copper striped antennas carefully equidistance which has been measured and marked through digital caliper at the corner of the preformed worksheet of square pyramid frusta as maximum forming occurs at the corners. The tool is made to move in predefined loci of the square pyramid (Fig 4). Continues signal in the waveform is captured by the antenna \& DSO in mille-volt range. Whenever the tool crosses the antenna, high voltage signals are noted.

The deformation starts from the outer to the center of the sheet. Since the center part having the small base length to deform, at this stage of forming of $0.2 \mathrm{~mm}$ sheet which 


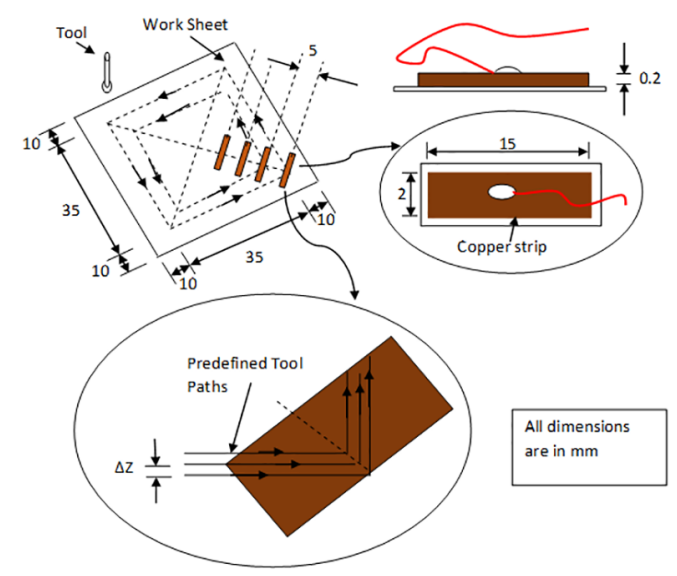

Figure 3. The Schematic diagram of antenna fixation on the sample piece to capture EMR.

is already deformed plastically. The emission of EMR is almost zero, so that the length of antenna 4 is shorter than other antennas (Fig. 4a) whereas the antenna 1 is carefully pasted as because the tool moves over it at the beginning where worksheet begins to deform. At this region, A13003 have an ultimate tensile strength of $136 \mathrm{MPa}$. Whenever tool moves over antenna 1 , the antenna is captured maximum voltage signals where the sheet deforms plastically. The different views of the formed part are shown in Figure 4b-d.

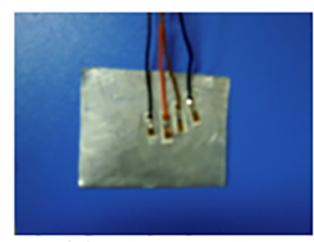

(a) Antenna setting

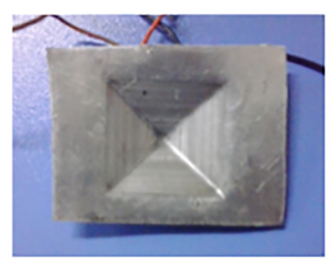

(c) Front View

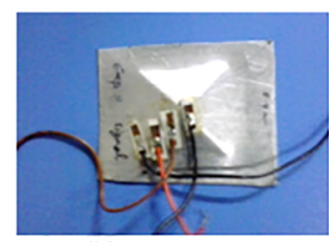

(b) Top View

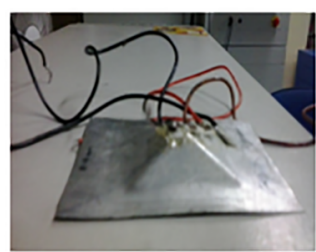

(d) Side View
Figure 4. a Actual representation of Antenna before forming, 4b-d different view of formed square pyramid frusta.

\subsection{Boost converter along with band pass filter}

The major difficulties experienced during the study are to differentiate the EMR signals generated during deformation and noise generated by electricity and vibration. Apart from this EMR signal generated are quite weak and has led to low voltage emission to be recorded by DSO. To overcome the difficulties, a boost converter with filter is developed and connected between DSO and the antenna (Fig. 5). The boost converter amplifies the actual voltage signals in Millivolt $(\mathrm{mV})$ to Volt $(\mathrm{V})$ range and filters the noise generated. The captured intermittent EMR signals are then stored in the hard drive by DSO which measures quantitatively electric voltage as a function of real time.
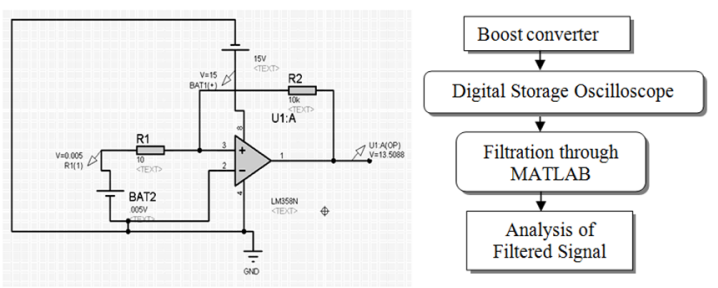

Figure 5. Bandpass filter circuit along with boost converter and Amplification scheme of captured signal.

\subsection{Input variables for experiments}

Experiments are conducted with input parameters as tabulated in Table 1. The axisymmetric square pyramid shapes loci of tool path are considered for determining the effect of step depth. From experiment number 1 and 2, it has been found that the emission of EMR starts after some contour formation, whereas, in experimental set 3 and 4 , a very good voltage signal is being recorded. The electromagnetic radiation emitted intermittently during the climbing motion, the accelerated edge dislocations, forming accelerated electric line dipole, which gives rise to EMR emissions. These experiments confirm that during deformation as slip line occurs or by grain breakages, emits good EMR.

Table 1. Process parameters of SMIMF.

\begin{tabular}{lcccc}
\hline Exp. No. & $\begin{array}{c}\text { Step depth } \\
(\mathrm{mm})\end{array}$ & $\begin{array}{c}\text { Feed rate } \\
(\mathrm{mm} / \mathrm{min})\end{array}$ & $\begin{array}{c}\text { RPM of } \\
\text { tool }\end{array}$ & Lubricant \\
\hline 1 & 0.1 & 20 & 500 & $\begin{array}{c}\text { Dry } \\
\text { Graphite } \\
\text { Powder } \\
2\end{array}$ \\
0.1 & 20 & 500 & 500 & $\begin{array}{c}\text { Dry } \\
\text { Graphite } \\
\text { Powder }\end{array}$ \\
\hline
\end{tabular}

\section{Result and Discussion}

Continues signals in the waveform are captured by the antenna \& DSO in $\mathrm{mV}$ range with noises. Whenever the tool crosses the antenna, high voltage signals are noted. The captured signals in real time are again filtered by using Matlab version 7.6.0.324 (R20008a). A Compatible program is developed in the Matlab to remove the noises i.e. EMR signals emitted in below a certain $\mathrm{mV}$ range. EMR signals after filtration are being shown in Fig. 6.

The impact of varying step depth on the EMR is then calculated using regression which confirms the step depth with voltage signals at apick in different forming conditions. 


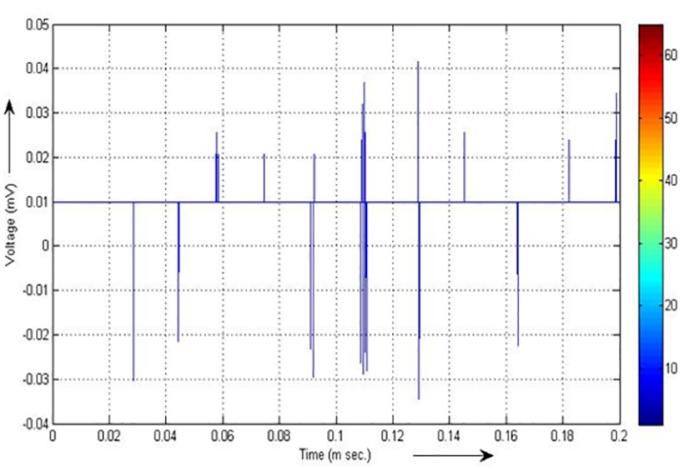

Figure 6. Refined EMR in real time scale.

EMR Signal captured in term of voltage for both dry and lubricated SMIF at $0.1 \mathrm{~mm} 0.7 \mathrm{~mm}$ step depth is summarized in Table 2. The maximum EMR peak occurs with $6.4 \mathrm{e}-4$ $\mathrm{mV}$ at the depth of $2.1 \mathrm{~mm}$ in dry condition and $3 \mathrm{e}-4 \mathrm{mV}$ at the depth of $2 \mathrm{~mm}$ in lubricated condition in case of $0.1 \mathrm{~mm}$ step depth, whereas In the case of $0.7 \mathrm{~mm}$ step depth, the maximum EMR peak occurs with $1 \mathrm{e}-2 \mathrm{mV}$ at depth of 1.8 $\mathrm{mm}$ in dry condition deformation and $3.2 \mathrm{e}-4 \mathrm{mV}$ at a depth of $3 \mathrm{~mm}$ with lubricated condition. The graphical representation of the effect of varying step depths with dry and lubrication condition on EMR signals are also shown in shown in Fig. 7.
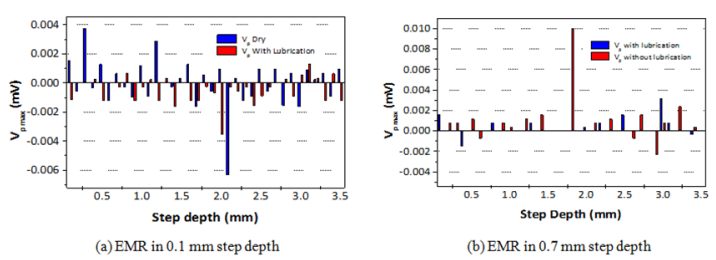

Figure 7. Filtered EMR signals for $0.1 \mathrm{~mm}$ step depth and 0.7 mm step depth.

The experimental investigation reveals that the step depth plays a vital role during the micro-deformation. Higher the step depth higher is the signal emitted during the deformation. The strength of signal found to be more during dry condition compared to the lubricated state of micro forming under same step depth. In the present study, the lubricant is used only for reducing the tool wear and assumed that the lubricant does not affect the strength of voltage signals. Further study is needed to understand the influences of various lubricants on the EMR.

\subsection{Crystallographic analysis}

Alloy Al 3003-O (iron 0.7\%and silicon $0.6 \%$ as impurities) have FCC (face-centered-cubic arrangement of atoms, common to most of the ductile metals) crystal structure. This means that the atoms are in the corners of a cube and one in the centre of each face. The length of the sides of the cube for high purity aluminum has been determined as $4.049 \times 10-8 \mathrm{~cm}$. The face-centered cubic structure is one of the arrangements assumed by close-packed spheres. The dislocation in crystals depends upon the direction of applied load. Definitely, the structural change in rolling direction (RD) of sheet differs from the LD (longitudinal direction) and ND (Normal direction) in the present case. In the present analysis, the microstructural changes are investigated by the SEM. ${ }^{30-33}$

The above experimental investigations confirm the emission of intermittent EMR signal from the metals. The internal microstructure of A13003 is investigated for the impact of microstructural properties such as mass per unit length of dislocation, line tension, damping coefficient, and the distance between the dislocation pinning points. ${ }^{20}$ The surface texture of both sides (deformed and opposite to deformed) of A13003 are observed by the scanning electron microscopy (SEM). The crystallographic surface structures by SEM are shown in Fig.8. The SEM not clarifies the effect of micro deformation on the work material (Fig. 8b \& 8d) and the crystalline dislocation after forming.

\subsection{Microstructure analysis}

The samples are prepared from formed part of A13003 by cutting the formed area carefully without damaging the formed area. The samples is cutting from longitudinal sections as defined by the rolling direction (RD) and the normal direction (ND)The sample pieces are mounted in the base of epoxy resins for the purpose and is observed in bright field after polishing the specimen initially with fine emery (up to 1200 grade)and finally with fine finishing using brasso chemical containing 4\% isopropyl alcohol, Ammonia 5\%, Silica powder $15 \%$ and Oxalic acid $2 \%$. Specimen is further etched by a standard Keller's reagent (Distilled water $190 \mathrm{ml}$, nitric acid $5 \mathrm{ml}$, hydrochloric acid $3 \mathrm{ml}$ and hydrofluoric acid $2 \mathrm{ml}$ ) for 5 seconds. Microstructure examination is carried out using an Olympus (Melville, NY, USA) inverted metallurgical microscopy.The 500X

Table 2. Results from regression analysis at $0.1 \mathrm{~mm}$ and $0.7 \mathrm{~mm}$ step depth.

\begin{tabular}{ccccccc}
\hline Material & $\begin{array}{c}\text { Step Depth } \\
(\mathrm{mm})\end{array}$ & Lubricant & Peak at & Width & Area & Height \\
\hline \multirow{4}{*}{ Al3003 } & 0.1 & Dry & 2.1 & 0.2 & $-1.78 \mathrm{E}-4$ & -0.0064 \\
& & Graphite Powder & 2 & 1.4 & -0.00278 & -0.0036 \\
& \multirow{2}{*}{0.7} & Dry & 1.8 & 0.2 & 0.00308 & 0.01 \\
& & Graphite Powder & 3 & 3 & 0.00094 & 0.0032 \\
\hline
\end{tabular}




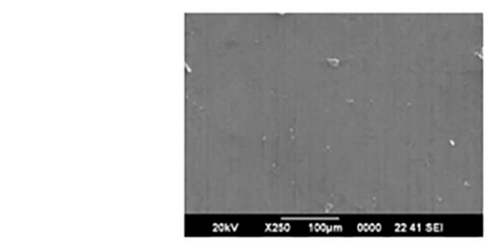

(a)

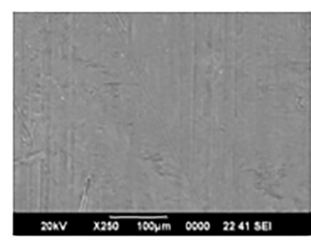

(b)

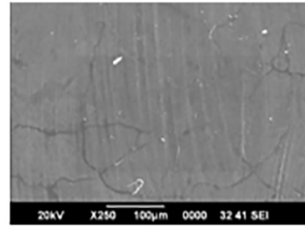

(d)

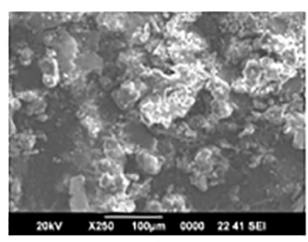

(c)

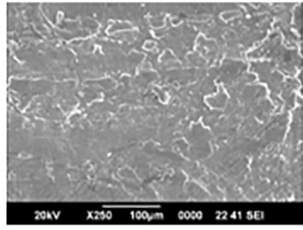

(e)
Figure 8. A13003-O without deformation; 8b-c Deformed (Toolblank contact)side of $0.1 \mathrm{~mm}$ and $0.7 \mathrm{~mm}$ step depth $8 \mathrm{~d}$-e: opposite to deformed side $0.1 \mathrm{~mm}$ and $0.7 \mathrm{~mm}$ step depth respectively.

magnification of $\mathrm{Al} 3003$ without any processing, i.e. in plain condition is presented in Fig.9a.Figure 9b-c show the micrographs of base side the formed area with $0.1 \mathrm{~mm}$ and $0.7 \mathrm{~mm}$ step depth whereas Figure 9d-e is the micrographs of thickness side with $0.1 \mathrm{~mm}$ and $0.7 \mathrm{~mm}$ step depth of the formed pyramid respectively.

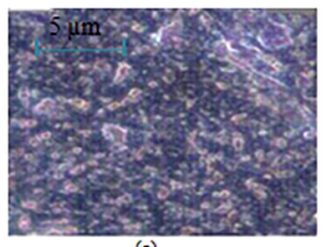

(a)

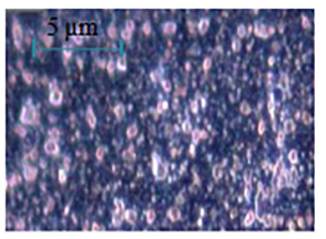

(b)

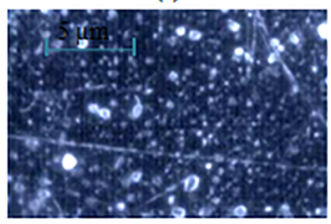

(d)

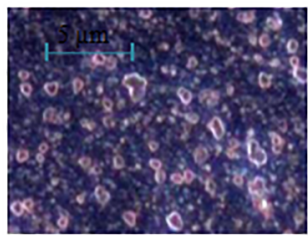

(c)

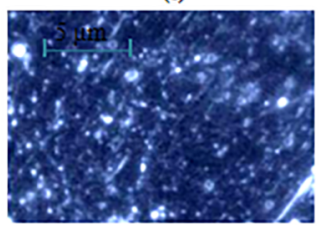

(e)
Figure 9. Al3003 without deformation; 9b-c Base side with 0.1 mm step depth and $0.7 \mathrm{~mm}$ step depth 9d-e: thickness side with $0.1 \mathrm{~mm}$ step depth and $0.7 \mathrm{~mm}$ step depth.
The microstructure of A13003 reveals that the dispersion of lattices is almost same in the plain $\mathrm{Al} 3003$ sheet. In the case of deformation with $0.1 \mathrm{~mm}$ step depth (Fig.9d), the grains of aluminum dispersed smoothly in rolling directions (RD), whereas deforming $0.7 \mathrm{~mm}$ step depth in $0.2 \mathrm{~mm}$ thick sheet, the grains of aluminium refines in longitudinal directions (LD) (Fig. 9e) but the dispersion of grains is as ascertain and appears more compression in LD which causes the higher EMR with $0.7 \mathrm{~mm}$ step depth.

Since these experiments are conducted for investigation of EMR signal during forming through SMIMF. Some of the aspects are not considered such as strains induced on the formed sheet; the hard to form, i.e. the brittle sheet material is not taken for the test.

Some of the major outcomes of the experimental investigation are as follows:

1. EMR emitted during the dry and lubricated condition of SMIMF is compared and observed that during dry condition, the signal emitted are more. This is due to frictional stress generated over the workpiece surface by the rotation of the tool which enhances the dislocation in the metals and hence emission of larger EMR. This shows that the material will fail with less deformation in dry condition compared with the lubricated condition.

2. It is observed that, during incremental forming of $0.2 \mathrm{~mm}$ thick Al3003 in dry state deformation, at $0.1 \mathrm{~mm}$ step depth, the maximum peak recorded at $2.1 \mathrm{~mm}$.

3. At $0.7 \mathrm{~mm}$ step depth, the maximum peak recorded at $1.8 \mathrm{~mm}$ depth with the voltage signal of $1 \mathrm{e}-2 \mathrm{mV}$.

4. The microstructural of formed Al sheet in the base side is different from thickness side of the work sheet.

\section{Conclusion}

From the experimental results and discussions described above, the following conclusions may be drawn:

i) Thin sections of metals and alloys also emit intermittent EMR during tearing or compressing. ii) Interface area of the tool-sheet during microforming and forming mechanism affect the EMR signal voltage.

iii) The intermittent EMR voltage signal range may vary with the thickness of the sheet.

iv) The intermittent EMR responses are influenced by the material anisotropy like intermolecular bonding such as microstructure, purity of material etc.

v) The EMR responses under microforming are influenced by the strain rate and depth of deformation (step depth).

vi) the EMR emission characteristics under an externally loaded work specimen within the plastic 
zone ahead of a crack tip form accelerated electric line dipoles, whatever the surface conditions of metals.

vii) The investigation confirms that EMR radiation is also generated in micro-deformation. This can be utilized to developed online inspection tool for the incremental micro forming process.

\section{Acknowledgement}

Authors acknowledge Dr. Ashok Misra for his valuable support. Authors also acknowledge Department of Science and Technology, Government of India for giving FIST II projects from which Micro tool equipment has been purchased.

\section{References}

1. Ambrogio G, Duflou JR, Filice L,Aerens R. Some considerations on force trends in Incremental Forming of different materials. AIP Conference Proceedings. 2007; 907:193-198.

2. Jeswiet J, Duflou JR, Szekeres A. Forces in Single Point and Two Point Incremental Forming. Advanced Material Research. 2005;6-8: 449-456.

3. Szekeres A, Ham M, Jeswiet J. Force measurement in pyramid shaped parts with a spindle mounted force sensor. Key Engineering Materials. 2007;344: 551-558.

4. Aerens R, Eyckens P, Bael AV, Duflou JR. Force prediction for single point incremental forming deduced from experimental and FEM observations. Journal of Advanced Manufacturing Technology. 2010; 46: 969-982.

5. Oraon M, Sharma V, Kumar S. Effect of tool geometry in sheet metal Incremental forming. proc. In: Proceedings of $27^{\text {th }}$ National Seminar on Advancements in Manufacturing - Vision 2020; 2012 May 25-26; Ranchi, India. Paper 03.

6. Oraon M, Sharma V. Effectiveness of tool profile in sheet metal incremental forming. In: Proceedings of $5^{\text {th }}$ International Scientific and Expert Conference of the International TEAM Society - TEAM 2013; 2013 Nov 04-06; Prešov, Slovakia. p. 55-59.

7. Duflou J, Tunckol Y, Szekeres A, Vanherck P. Experimental study on force measurement for single point incremental forming. Journal of Materials Processing Technology.2007; 189(1-3):65-72.

8. Rattanachan K, Chung C. Formability in Single Point Incremental Forming of Dome Geometry. Asian International Journal of Science and Technology in Production and Manufacturing Engineering. 2009;2(4):57-63.

9. Hussain G, Gao L, Dar NU. An experimental study on some formability evaluation methods in negative incremental forming. Journal of Materials Processing Technology. 2007;186(1-3):4553.

10. Pohlak M, Majak J, Kuttner R. Manufacturability and limitations in incremental sheet forming. Proceedings of the Estonian Academy of Science and Engineering. 2007;13(2):129-139.
11. Pguyen DT, Park JG, Kim YS. Ductile Fracture Prediction in Rotational Incremental Forming for Magnesium Alloy Sheets Using Combined Kinematic/Isotropic Hardening Model. Metallurgical and Materials Transactions A.2010;41(9):19831994.

12. Malhotra R, Xue L,Belytschko T, Cao J. Mechanics of fracture in single point incremental forming. Journal of Materials Processing Technology. 2012;212(7):1573-1590.

13. Durante M, Formisano A, Langella A, Minutolo FMC. The influence of tool rotation on an incremental forming process. Journal of Materials Processing Technology. 2009; 209(9):46214626.

14. Jeswiet J, Young D. Forming limit diagrams for single point incremental forming of aluminum sheet. Proceedings of the Institution of Mechanical Engineers, Part B: Journal of Engineering Manufacture. 2005; 219(4):359-364.

15. Kurra S,Srinivasa P,Regalla SP. Experimental and numerical studies on formability of extra-deep drawing steel in incremental sheet metal forming. Journal of Materials Research and Technology. 2014; 3(2):158-171.

16. Khalatbari H. Investigation of Formability of Material in Incremental Sheet Metal Forming Process. [Dissertation]. Gazimagusa: Eastern Mediterranean University; 2012.

17. Misra A. A physical model for the stress-induced electromagnetic effect in metals. Applied Physics. 1978;16(2):195-199.

18. Molotskii MI. Dislocation mechanism for the Misra effect. Soviet Technical Physics Letters. 1980; 6:22-23.

19. Misra D, Misra A. Stress-induced electromagnetic effect- a new biophysical application to head injury. Neurology India. $1980 ; 28: 234-241$.

20. Misra A. Electromagnetic effects at metallic fracture. Nature. 1975; 254:133-134.

21. Misra A. On the Magnetism Produced in Unmagnetized Iron Specimens at Breakage Under Tension. Indian Journal of Pure and Applied Physics. 1973; 11:419-422.

22. Misra A, Kumar A. Some basic aspects of electromagnetic radiation during crack propagation in metals. International Journal of Fracture. 2004; 127(4):384-401.

23. Misra A, Prasad RC, ChauhanVS, Srilakshmi B. A theoretical model for the electromagnetic radiation emission during plastic deformation and crack propagation in metallic materials. International Journal of Fracture. 2007; 145(2):99-121.

24. Chauhan VS, Misra A. Electromagnetic radiation during plastic deformation under unrestricted quasi-static compression in metals and alloys. International Journal of Materials Research. 2010;101(7):857-864.

25. Kumar R, Misra A. Effect of processing parameters on the electromagnetic radiation emission during plastic deformation and crack propagation in copper-zinc alloys. Journal of Zhejiang University-SCIENCE A.2006;7(11):1800-1809

26. Kumar R, Misra A. Some basic aspects of electromagnetic radiation emission during plastic deformation and crack propagation in $\mathrm{Cu}-\mathrm{Zn}$ alloys. Materials Science and Engineering: A. 2007;454-455:203-210. 
27. Srilakshmi B, Misra A. Secondary electromagnetic radiation during plastic deformation and crack propagation in uncoated and tin coated plain carbon steel. Journal of Materials Science. 2005; 40(23):6079-6086.

28. Chauhan VS, Misra A. Effect of strain rate and elevated temperature electromagnetic radiation emission during plastic deformation and crack propagation in ASTM B265 grade 2 titanium sheet. Journal of Materials Science. 2008; 43(16):5634-5443.

29. Mishra SK, Sharma V, Misra A. Effect of rate of deformation on electromagnetic radiation during quasi-static compression of sintered aluminium performs. International Journal of Materials Research. 2014; 105(3):265-271.

30. Hamilton KAS. Friction and external surface roughness in single point incremental forming: A study of surface friction, contact area and the 'orange peel' effect. [Thesis]. Kingston: Queen's University; 2010.

31. Oleksik V, Pascu A, Deac R, Fleaca R, Bologa O, Racz G. Experimental study on the surface quality of the medical implants obtained by single point incremental forming. International Journal of Material Forming. 2010;3(Suppl 1):935-938.

32. Durante M, Formisano A, Langella A. Comparison between analytical and experimental roughness values of components created by incremental forming. Journal of Materials Processing Technology. 2010; 210(14):1934-1941.

33. Hamilton K, Jeswiet J. Single point incremental forming at high feed rates and rotational speeds: Surface and structural consequences. CIRP Annals. 2010; 59(1):311-314. 